\title{
Individual Traits and Pain Treatment: The Case of Hypnotizability
}

\author{
Enrica Laura Santarcangelo ${ }^{1 *}$ and Giancarlo Carli ${ }^{2}$ \\ ${ }^{1}$ Department of Translational Research and New Technologies in Medicine and Surgery, University of Pisa, Pisa, Italy, \\ ${ }^{2}$ Department of Medicine, Surgery and Neuroscience, University of Siena, Siena, Italy
}

Keywords: hypnotic susceptibility, cognitive pain control, suggestions, analgesia, imagery, autonomic, immune system, cortical plasticity

\section{INTRODUCTION}

Pharmacological, physical and cognitive treatments reduce pain by addressing all pain dimensions. Nonetheless, drugs may be ineffective, and physical activity is not always viable. In contrast, cognitive therapies have usually good outcomes, a wide range of applicability and no side effects. Their efficacy, however, is influenced by cognitive and psychophysiological traits. In this Opinion article hypnotizability is used as a model to support the view that specific psychophysiological traits and cognitive strategies can not only reduce pain, but also modulate the pain-related autonomic and immune activity, induce cortical plasticity relevant to pain control, and assist in the choice of the most appropriate treatment.

OPEN ACCESS

Edited by:

Anat Galor,

University of Miami, United States

Reviewed by:

Graham Alexander Jamieson, University of New England, Australia Donald Patrick Moss,

Saybrook University, United States Enrico Facco,

University of Padua, Italy

*Correspondence: Enrica Laura Santarcangelo enrica.santarcangelo@unipi.it

Specialty section:

This article was submitted to Neuropharmacology,

a section of the journal

Frontiers in Neuroscience

Received: 19 March 2021 Accepted: 05 May 2021

Published: 02 June 2021

Citation: Santarcangelo EL and Carli G (2021) Individual Traits and Pain Treatment: The Case of Hypnotizability.

Front. Neurosci. 15:683045

doi: 10.3389/fnins.2021.683045
Hypnotizability, or hypnotic susceptibility, is a multidimensional trait stable through life (Piccione et al., 1989) and measured by validated scales (Elkins et al., 2015) classifying highly (highs), medium (mediums), and low hypnotizable subjects (lows). It is associated with brain morpho-functional peculiarities (Landry et al., 2017; Picerni et al., 2019) and displays correlates in the sensorimotor (Ibáñez-Marcelo et al., 2019; Santarcangelo and Scattina, 2019), cardiovascular (Jambrik et al., 2004a,b, 2005; Santarcangelo et al., 2012) and cognitive-emotional domain (Diolaiuti et al., 2019). Both highs and lows represent about $15 \%$ of the population which consists mainly of mediums (70\%).

In healthy subjects the ability to control pain through suggestions for analgesia is linearly correlated with hypnotizability scores (Fidanza et al., 2017). Hypnotic treatments, however, are particularly important for patients with neuropathic and musculo-skeletal pain (Castel et al., 2007; Carli et al., 2008; Jensen et al., 2009a,b; Jensen and Patterson, 2014), which are seldom responsive to pharmacological treatments. They have been found more effective than any other psychological intervention (Jensen et al., 2020), although high hypnotizability predicts better outcomes also in patients, owing to the highs' greater high proneness to modify their bodily condition according to suggestions, and, thus, to relax (De Benedittis et al., 1994), to their peculiar imagery abilities (Ibáñez-Marcelo et al., 2019), and to their attitude to be deeply absorbed in their own mental images (Vanhaudenhuyse et al., 2019).

\section{SUGGESTIONS FOR ANALGESIA}

The suggestions for analgesia are requests to imagine that the experienced pain is out of the body or limited to a small part of it, or that a glove prevents one to perceive any nociceptive stimulation.

They are effective on acute/procedural, post-surgery and chronic pain (Jensen and Patterson, 2014; Facco, 2016) and, as most suggestions (Green and Lynn, 2011; Santarcangelo, 2014), can be efficaciously administered in the ordinary state of consciousness, thus not necessarily following the induction of the hypnotic state (Derbyshire et al., 2009; Paoletti et al., 2010; Santarcangelo et al., 2012). In highs, suggestions-induced analgesia, which can be focused on the sensory and/or 
emotional dimension of pain, is not accompanied by release of endogenous opiates, but is sustained by the modulation of the activity and connectivity of the pain matrix (Faymonville et al., 2006; Casiglia et al., 2020).

Interestingly, the suggestions for analgesia have been found effective also in healthy mediums undergoing nociceptive stimulation (Fidanza et al., 2017) and in chronic pain patients independently from hypnotizability (Elkins et al., 2007; Jensen, 2011; Jensen and Patterson, 2014; Mazzola et al., 2017; Facco et al., 2018; Sandvik et al., 2020). This can be accounted for by expectation of/motivation to analgesia (Milling et al., 2005; Krystek and Kumar, 2016; Montgomery et al., 2018; Perri et al., 2020) leading to placebo responses (Benedetti, 2013) which can reduce pain and pain-related psychological symptoms in the general population (Liossi et al., 2006; Brugnoli, 2016; Wortzel and Spiegel, 2017; Rousseaux et al., 2020). Thus, suggestions may induce non opioid analgesia in highs, opioid placebo responses in lows and, probably, mixed reactions in mediums. It is particularly interesting, in this respect, that, during hypnotic sessions, oxytocin - the hormone promoting social relationships and acquiescent behavior - is released in the hypnotist and the client and that, in the latter, the lower the hypnotizability score the larger the OXT release. A further contribution to the hypnotist-client relation could be the level of intimacy which has been associated with the polymorphism of the serotonin transporter 5-HTTLPR gene. Its variant associated with greater efficiency is not significantly associated with hypnotizability but may enhance the experience of "rapport" independently from it (Katonai et al., 2017). In brief, suggested analgesia occurs in the general population, although through different mechanisms (Santarcangelo and Consoli, 2018). In addition, in contrast to "constructive imagery" (inducing sensory experiences in the absence of actual stimulations), obstructive suggestions such as analgesia and anesthesia aimed at reducing the perception of actual sensory stimulations can be experienced also by lows if they report mental images as vivid as highs do (Santarcangelo et al., 2010). Thus, in lows, imagery and placebo responses could co-operate in the response to suggestions for analgesia.

\section{NEUROTRANSMITTERS}

In the absence of explicit suggestions for analgesia, hypnotizability related differences in pain thresholds (Hilgard, 1967; Agargün et al., 1998; Santarcangelo et al., 2013; Kramer et al., 2014) and perceived pain intensity (Santarcangelo et al., 2010) have been seldom reported. Several studies, however, describe hypnotizability-related differences in genetic polymorphisms and brain neurotransmitters content which may be relevant to pain control in the presence of suggestions and/or to the choice of pain treatments. In fact:

a. highs display the variant of OPMR1 receptors (A118G, rs1799971) characterized by low sensitivity to opiates, high consumption of opioids for post-surgery and cancer pain and low placebo responsiveness more frequently than lows, with mediums displaying intermediate frequencies (Santarcangelo and Consoli, 2018). Thus, opioid treatments are not the most appropriate in highs.

b. the Fatty-Acids- Amino-Hydrolase (FAAH) C385A polymorphism (rs324420) responsible for endocannabinoids (eCBs) degradation is not significantly different between hypnotizability groups but the polymorphism frequencies indicate a trend to higher degradation efficiency from lows to highs (Presciuttini et al., 2020). We may hypothesize that small differences in the eCBs content could be amplified by the eCBs interactions with nor-adrenegic (Scavone et al., 2013) and dopaminergic pathways (Di Filippo et al., 2008). Thus, a contribution of the FAAH polymorphism to the highs' ability to control pain by suggestions for analgesia should not be excluded.

c. oxytocin (OXT), which modulates the sensory and emotional components of pain (Poisbeau et al., 2018), can contribute to the highs' suggestions induced analgesia through activation of the endogenous opioid system and by regulating the eCBs production (Russo et al., 2012). In fact, the polymorphism of the OXT receptor gene associated with high sensitivity (rs53576) is more frequent in highs than in the general population (Bryant et al., 2013).

d. brain nitric oxide (NO) promotes the release of brain dopamine and noradrenaline (Ghasemi et al., 2019), which are involved in pain control. According to post-occlusion flow mediated dilation (FMD), the endothelial NO release at peripheral level is reduced in lows and in the general population, but not in highs (Jambrik et al., 2004a,b; Jambrik et al., 2005). If confirmed at brain level, a continuous release of endothelial NO might amplify the availability of noradrenaline and dopamine in highs.

\section{AUTONOMIC AND IMMUNE ACTIVITY}

The autonomic and immune activity are strictly related to each other (Pavlov et al., 2018; Walters, 2018; Blake et al., 2019; Elkhatib and Case, 2019; Iovino et al., 2020) in that the former modulates the immune activity (Elenkov et al., 2000; Jänig, 2014; Martelli et al., 2014) and the latter can regulate the function of brain autonomic centers (Elsaafien et al., 2019).

The mechanisms controlling acute inflammation and the associated pain are quite different from those controlling chronic inflammation and chronic pain. In particular, the proinflammatory cytokines produced in response to an acute body lesion excite the central nervous system by the activation of vagal afferents and, after penetration through the blood brain barrier, of brain structures which, in turn, generate anti-inflammatory responses. The networks involved in the inflammatory inhibition are: (a) the parasympathetic circuit, limited to vagal afferents and efferents; (b) the parasympathetic-neuroendocrine circuit, which is responsible for the release of corticosteroids; (c) the cytokinevagal-sympathetic circuit, involving noradrenergic pathways and adrenal epinephrine (Pavlov et al., 2018). In the latter circuit, the mechanisms inhibiting acute inflammation and pain are distinct, triggered by specific contextual/environmental stimuli in animals and by psychological interventions in humans (Bassi et al., 2018). 
High hypnotizability is associated with pre-eminent parasympathetic control of heart rate during relaxation in the awake condition with respect to lows (Santarcangelo et al., 2012), with a further shift toward parasympathetic tone after hypnotic induction (De Benedittis et al., 1994), and with greater proneness to reduce sympathetic activation during suggestions of unpleasant experiences associated with instructions for relaxation and well-being (Sebastiani et al., 2007). In contrast, and at variance with cortical and somatic correlates (Santarcangelo and Consoli, 2018), the findings of hypnotizability-related reduction of sympathetic activity associated with suggestion-induced analgesia in healthy subjects are inconsistent (De Pascalis et al., 2001; Paoletti et al., 2010; Santarcangelo et al., 2013). Theoretically, however, the autonomic peculiarities of high hypnotizable individuals - parasympathetic prevalence - should be associated with a more effective immune activity. Hypnotic treatments, in fact, upregulate the expression of immune-related genes in lymphocytes (Kovács et al., 2008), reduce salivary cortisol (Thompson et al., 2011) and immunoglobulin A in surgical patients with breast cancer (Minowa and Koitabashi, 2014), regulate auto-immune disorders (Torem, 2007), human papillomavirus (Barabasz et al., 2010), and proinflammatory/anti-inflammatory cytokines in elders (Sari et al., 2017).

\section{CORTICAL PLASTICITY}

An ambitious target for chronic pain treatments should be counteracting the disadvantageous cortical plasticity associated with chronic pain, consisting of alteration in the brain gray matter volume (Xiong et al., 2017; McCarberg and Peppin, 2019; Yin et al., 2020) and in long-term potentiation in the anterior cingulate cortex and insular cortex (Zhuo, 2020).

In chronic pain patients Transcranial Magnetic Stimulation (TMS) and electrical direct Transcranial Stimulation (dTCS) are efficaciously used to modulate the activity of pain-related circuits (Klein et al., 2015; Dos Santos et al., 2018; Meeker et al., 2020) together with vagal stimulation (Costa et al., 2019). Theoretically, imaginatively induced analgesia could influence

\section{REFERENCES}

Agargün, M. Y., Tekeoglu, I., Kara, H., Adak, B., and Ercan, M. (1998). Hypnotizability, pain threshold, and dissociative experiences. Biol. Psychiat. 44, 69-71. doi: 10.1016/S0006-3223(97)00511-8

Barabasz, A., Higley, L., Christensen, C., and Barabasz, M. (2010). Efficacy of hypnosis in the treatment of human papillomavirus (HPV) in women: rural and urban samples. Int. J. Clin. Exp. Hypn. 58,102-121. doi: 10.1080/00207140903310899

Bassi, G. S., Kanashiro, A., Rodrigues, G. J., Cunha, F. Q., Coimbra, N. C., and Ulloa, L. (2018). Brain stimulation differentially modulates nociception and inflammation in aversive and non-aversive behavioral conditions. Neuroscience 383, 191-204. doi: 10.1016/j.neuroscience.2018.05.008

Beltran Serrano, G., Pooch Rodrigues, L., Schein, B., Zortea, M., Torres, I. L. S., Fregni, F., et al. (2020). The hypnotic analgesia suggestion mitigated the effect of the andranscranial direct current stimulation on the descending pain cortical plasticity (Kleim and Jones, 2008) mimicking the effects of TMS and dTCS by suggestions aimed at modulating the activity of the pain matrix (Casiglia et al., 2020) and enhancing the action of descending antinociceptive pathways (Beltran Serrano et al., 2020). The highs' stronger functional equivalence between imagery and perception/action (Ibáñez-Marcelo et al., 2019) and their greater cortical excitability (Spina et al., 2020), in fact, allow them to experience pleasant situations able to buffer the activity of the pain matrix, thus promoting the cognitive reappraisal of their pain condition. In addition, the activity of the pain matrix itself can be reduced by suggestions (Faymonville et al., 2006; Casiglia et al., 2020) and co-operate to promote long-lasting effects. Suggestive treatment of pain, in fact, induces long-lasting analgesic effects addressing all pain dimensions (Dillworth and Jensen, 2010; Jensen et al., 2014). Of note, cortical long-lasting plasticity is induced also by neutral hypnosis that is the state experienced by highs after hypnotic induction in the absence of specific suggestions (Jiang et al., 2017).

\section{CONCLUSIONS}

The pain matrix structure, activity and connectivity (Legrain et al., 2011) are influenced by acute and chronic pain. Our opinion is that that pain experience and physiology are modulated by the physiological correlates of hypnotizability, and that hypnotic assessment may assist in the choice of the most appropriate pharmacological treatments (a); the suggestions for analgesia are effective in both wakefulness and hypnosis and can control pain in a large majority of the general population, although through different mechanisms (b); hypnotizability is an advantageous factor in the control of pain-related autonomic and immune functions (c); hypnotizability-related cortical plasticity may counteract the effects of chronic pain on the structure and function of the pain matrix (d). In conclusion, suggestions for analgesia should be considered for any pain patient and not only after unsuccessful pharmacological treatments.

\section{AUTHOR CONTRIBUTIONS}

The authors equally contributed to the paper and agreed on its content.

modulatory system: a proof-of-concept study. J. Pain. Res. 13, 2297-2311. doi: 10.2147/JPR.S253747

Benedetti, F. (2013). Placebo and the new physiology of the doctor-patient relationship. Physiol. Rev. 93, 1207-1246. doi: 10.1152/physrev.00043. 2012

Blake, K. J., Jiang, X. R., and Chiu, I. M. (2019). Neuronal regulation of immunity in the skin and lungs. Trends Neurosci. 42, 537-551. doi: 10.1016/j.tins.2019.05.005

Brugnoli, M. P. (2016). Clinical hypnosis for palliative care in severe chronic diseases: a review and the procedures for relieving physical, psychological and spiritual symptoms. Ann. Palliat. Med. 5, 280-297. doi: 10.21037/apm.2016.09.04

Bryant, R. A., Hung, L., Dobson-Stone, C., and Schofield, P. R. (2013). The association between the oxytocin receptor gene (OXTR) and hypnotizability. Psychoneuroendocrinology 38,1979-1984. doi: 10.1016/j.psyneuen.2013. 03.002 
Carli, G., Suman, A. L., Biasi, G., Marcolongo, R., and Santarcangelo, E. L. (2008). Paradoxical experience of hypnotic analgesia in low hypnotizable fibromyalgic patients. Arch. Ital. Biol. 146, 75-82.

Casiglia, E., Finatti, F., Tikhonoff, V., Stabile, M. R., Mitolo, M., Albertini, F., et al. (2020). mechanisms of hypnotic analgesia explained by functional magnetic resonance (fMRI). Int. J. Clin. Exp. Hypn. 68, 1-15. doi: 10.1080/00207144.2020.1685331

Castel, A., Pérez, M., Sala, J., Padrol, A., and Rull, M. (2007). Effect of hypnotic suggestion on fibromyalgic pain: comparison between hypnosis and relaxation. Eur. J. Pain 11, 463-468. doi: 10.1016/j.ejpain.2006.06.006

Costa, B., Ferreira, I., Trevizol, A., Thibaut, A., and Fregni, F. (2019). Emerging targets and uses of neuromodulation for pain. Expert. Rev. Neurother. 19, 109-118. doi: 10.1080/14737175.2019.1567332

De Benedittis, G., Cigada, M., Bianchi, A., Signorini, M. G., and Cerutti, S. (1994). Autonomic changes during hypnosis: a heart rate variability power spectrum analysis as a marker of sympatho-vagal balance. Int. J. Clin. Exp. Hypn. 42, 140-152. doi: 10.1080/00207149408409347

De Pascalis, V., Magurano, M. R., Bellusci, A., and Chen, A. C. (2001). Somatosensory event-related potential and autonomic activity to varying pain reduction cognitive strategies in hypnosis. Clin. Neurophysiol. 112, 1475-1485. doi: 10.1016/S1388-2457(01)00586-7

Derbyshire, S. W., Whalley, M. G., and Oakley, D. A. (2009). Fibromyalgia pain and its modulation by hypnotic and non-hypnotic suggestion: an fMRI analysis. Eur. J. Pain 13, 542-550. doi: 10.1016/j.ejpain.2008.06.010

Di Filippo, M., Picconi, B., Tozzi, A., Ghiglieri, V., Rossi, A., and Calabresi, P. (2008). The endocannabinoid system in Parkinson's disease. Curr. Pharm. Des. 14, 2337-2347. doi: 10.2174/138161208785740072

Dillworth, T., and Jensen, M. P. (2010). The role of suggestions in hypnosis for chronic pain: a review of the literature. Open Pain J. 3, 39-51. doi: 10.2174/1876386301003010039

Diolaiuti, F., Huber, A., Ciaramella, A., Santarcangelo, E. L., and Sebastiani, L. (2019). Hypnotisability-related interoceptive awareness and inhibitory/activating emotional traits. Arch. Ital. Biol. 157, 111-119. doi: $10.12871 / 00039829202042$

Dos Santos, M. F., Oliveira, A. T., Ferreira, N. R., Carvalho, A. C. P., and Rosado de Castro, P. H. (2018). The contribution of endogenous modulatory systems to TMS- and tDCS-Induced analgesia: evidence from PET studies. Pain Res. Manag. 2018:2368386. doi: 10.1155/2018/2368386

Elenkov, I. J., Wilder, R. L., Chrousos, G. P., and Vizi, E. S. (2000). The sympathetic nerve-an integrative interface between two supersystems: the brain and the immune system. Pharmacol. Rev 52, 595-638.

Elkhatib, S. K., and Case, A. J. (2019). Autonomic regulation of T-lymphocytes: implications in cardiovascular disease. Pharmacol Res. 146:104293. doi: 10.1016/j.phrs.2019.104293

Elkins, G., Jensen, M. P., and Patterson, D. R. (2007). Hypnotherapy for the management of chronic pain. Int. J. Clin. Exp. Hypn. 55, 275-287. doi: 10.1080/00207140701338621

Elkins, G. R., Barabasz, A. F., Council, J. R., and Spiegel, D. (2015). Advancing research and practice: the revised apa division 30 definition of hypnosis. Am. J. Clin. Hypn. 57, 378-385. doi: 10.1080/00029157.2015.1011465

Elsaafien, K., Korim, W. S., Setiadi, A., May, C. N., and Yao, S. T. (2019). Chemoattraction and recruitment of activated immune cells, central autonomic control, and blood pressure regulation. Front. Physiol. 10:984. doi: 10.3389/fphys.2019.00984

Facco, E. (2016). Hypnosis and anesthesia: back to the future. Minerva Anestesiol. $82,1343-1356$

Facco, E., Casiglia, E., Zanette, G., and Testoni, I. (2018). On the way of liberation from suffering and pain: role of hypnosis in palliative care. Ann. Palliat. Med.7, 63-74. doi: 10.21037/apm.2017.04.07

Faymonville, M., Boly, M., and Laureys, S. (2006). Functional neuroanatomy of the hypnotic state. J. Physiol. 99, 463-469. doi: 10.1016/j.jphysparis.2006.03.018

Fidanza, F., Varanini, M., Ciaramella, A., Carli, G., and Santarcangelo, E. L. (2017). Pain modulation as a function of hypnotizability: diffuse noxious inhibitory control induced by cold pressor test vs explicit suggestions of analgesia. Physiol. Behav. 171, 135-141. doi: 10.1016/j.physbeh.2017.01.013

Ghasemi, M., Claunch, J., and Niu, K. (2019). Pathologic role of nitrergic neurotransmission in mood disorders. Prog. Neurobiol. 173, 54-87. doi: $10.1016 /$ j.pneurobio.2018.06.002
Green, J. P., and Lynn, S. J. (2011). Hypnotic responsiveness: expectancy, attitudes, fantasy proneness, absorption, and gender. Int. J. Clin. Exp. Hypn. 59, 103-121. doi: 10.1080/00207144.2011.522914

Hilgard, E. R. (1967). A quantitative study of pain and its reduction through hypnotic suggestion. Proc. Natl. Acad. Sci. U. S. A. 57, 1581-1586. doi: 10.1073/pnas.57.6.1581

Ibáñez-Marcelo, E., Campioni, L., Phinyomark, A., Petri, G., and Santarcangelo, E. L. (2019). Topology highlights mesoscopic functional equivalence between imagery and perception: the case of hypnotizability. Neuroimage 200, 437-449. doi: 10.1016/j.neuroimage.2019.06.044

Iovino, M., Messana, T., De Pergola, G., Iovino, E., Guastamacchia, E., and Licchelli, B., et al. (2020). Brain angiotensinergic regulation of the immune system: implications for cardiovascular and neuroendocrine responses. Endocr. Metab. Immune Disord. Drug Targets 20, 15-24. doi: 10.2174/1871530319666190617160934

Jambrik, Z., Chunzeng, L., Santarcangelo, E. L., Sebastiani, L., Ghelarducci, B., and Picano, E. (2004b). Traditional acupuncture does not modulate the endothelial dysfunction induced by mental stress. Int. J. Cardiovasc. Imag. 20, 357-362. doi: 10.1023/B:CAIM.0000041939.61963.b0

Jambrik, Z., Santarcangelo, E. L., Ghelarducci, B., Picano, E., and Sebastiani, L. (2004a). Does hypnotizability modulate the stressrelated endothelial dysfunction? Brain Res. Bull. 63, 213-216. doi: 10.1016/j.brainresbull.2004.01.011

Jambrik, Z., Santarcangelo, E. L., Rudisch, T., Varga, A., Forster, T., and Carli, G. (2005). Modulation of pain-induced endothelial dysfunction by hypnotisability. Pain 116, 181-186. doi: 10.1016/j.pain.2005.03.041

Jänig, W. (2014). Sympathetic nervous system and inflammation: a conceptual view. Auton. Neurosci. 182, 4-14. doi: 10.1016/j.autneu.2014.01.004

Jensen, M. P. (2011). Hypnosis for Chronic Pain Management: Therapist Guide. New York, NY: Oxford University Press. doi: 10.1093/med:psych/9780199772377.001.0001

Jensen, M. P., Barber, J., Romano, J. M., Hamley, M. A., Raichle, K. A., Molton, I. R., et al. (2009a). Effects of self-hypnosis training and EMG biofeedback relaxation training on chronic pain in persons with spinal-cord injury. Int. J. Clin. Exp. Hypn. 57, 239-268. doi: 10.1080/00207140902881007

Jensen, M. P., Barber, J., Romano, J. M., Molton, I. R., Raichle, K. A., Osborne, T. L., et al. (2009b). A comparison of self-hypnosis versus progressive muscle relaxation in patients with multiple sclerosis and chronic pain. Int. J. Clin. Exp. Hypn. 57, 198-221. doi: 10.1080/00207140802665476

Jensen, M. P., Day, A. M., and Miró, J. (2014). Neuromodulatory treatments for chronic pain: efficacy and mechanisms. Nat. Rev. Neurol. 10, 167-178. doi: 10.1038/nrneurol.2014.12

Jensen, M. P., Mendoza, M. E., Ehde, D. M., Patterson, D. R., Molton, I. R., Dillworth, T. M., et al. (2020). Effects of hypnosis, cognitive therapy, hypnotic cognitive therapy, and pain education in adults with chronic pain: a randomized clinical trial. Pain 161, 2284-2298. doi: 10.1097/j.pain.0000000000001943

Jensen, M. P., and Patterson, D. R. (2014). Hypnotic approaches for chronic pain management: clinical implications of recent research findings. Am. Psychol. 69, 167-177. doi: 10.1037/a0035644

Jiang, H., White, M. P., Greicius, M. D., Waelde, L. C., and Spiegel, D. (2017). Brain activity and functional connectivity associated with hypnosis. Cereb. Cortex 27, 4083-4093. doi: 10.1093/cercor/bhw220

Katonai, E. R., Szekely, A., Vereczkei, A., Sasvari-Szekely, M., Bányai, É. I., and Varga, K. (2017). Dopaminergic and serotonergic genotypes and the subjective experiences of hypnosis. Int. J. Clin. Exp. Hypn. 65, 379-397. doi: 10.1080/00207144.2017.1348848

Kleim, J. A., and Jones, T. A. (2008). Principles of experience-dependent neural plasticity: implications for rehabilitation after brain damage. J. Speech Lang. Hear. Res. 51, S225-S239. doi: 10.1044/1092-4388(2008/018)

Klein, M. M., Treister, R., Raij, T., Pascual-Leone, A., Park, L., Nurmikko, T., et al. (2015). Transcranial magnetic stimulation of the brain: guidelines for pain treatment research. Pain 156, 1601-1614. doi: 10.1097/j.pain.0000000000000210

Kovács, Z. A., Puskás, L. G., Juhász, A., Rimanóczy, A., Hackler L., Jr., Kátay, L., et al. (2008). Hypnosis upregulates the expression of immune-related genes in lymphocytes. Psychother. Psychosom. 77, 257-259. doi: 10.1159/0001 28165 
Kramer, S., Zims, R., Simang, M., Rüger, L., and Irnich, D. (2014). Hypnotic relaxation results in elevated thresholds of sensory detection but not of pain detection. BMC Complement Altern. Med. 14:496. doi: 10.1186/1472-6882-14-496

Krystek, S., and Kumar, V. K. (2016). A comparison of hypnotic induction, task motivation, and a "Cold Start" control group on hypnotizability. Am. J. Clin. Hypn. 59, 214-230. doi: 10.1080/00029157.2016.1200960

Landry, M., Lifshitz, M., and Raz, A. (2017). Brain correlates of hypnosis: a systematic review and meta-analytic exploration. Neurosci. Biobehav. Rev. 81, 75-98. doi: 10.1016/j.neubiorev.2017.02.020

Legrain, V., Iannetti, G. D., Plaghki, L., and Mouraux, A. (2011). The pain matrix reloaded: a salience detection system for the body. Progr. Neurobiol. 93, 111-124. doi: 10.1016/j.pneurobio.2010.10.005

Liossi, C., White, P., and Hatira, P. (2006). Randomized clinical trial of local anesthetic versus a combination of local anesthetic with self-hypnosis in the management of pediatric procedure-related pain. Health Psychol. 25, 307-315. doi: 10.1037/0278-6133.25.3.307

Martelli, D., McKinley, M. J., and McAllen, R. M. (2014). The cholinergic anti-inflammatory pathway: a critical review. Auton. Neurosci. 182, 65-69. doi: 10.1016/j.autneu.2013.12.007

Mazzola, L. A., Calcagno, M. L., Obdrzalek, A., Pueyrredón, J. H., Cavanagh, S., et al. (2017). Hypnosis for chronic pain management. Physiother. Rehabil. 2:128. doi: 10.4172/2573-0312.1000128

McCarberg, B., and Peppin, J. (2019). Pain pathways and nervous system plasticity: learning and memory in pain. Pain Med. 20, 2421-2437. doi: $10.1093 / \mathrm{pm} / \mathrm{pnz} 017$

Meeker, T. J., Jupudi, R., Lenz, F. A., and Greenspan, J. D. (2020). New developments in non-invasive brain stimulation in chronic pain. Curr. Phys. Med. Rehabil. Rep. 8, 280-292. doi: 10.1007/s40141-020-00260-w

Milling, L. S., Kirsch, I., Allen, G. J., and Reutenauer, E. L. (2005). The effects of hypnotic and nonhypnotic imaginative suggestion on pain. Ann. Behav. Med. 29, 116-127. doi: 10.1207/s15324796abm2902_6

Minowa, C., and Koitabashi, K. (2014). The effect of autogenic training on salivary immunoglobulin A in surgical patients with breast cancer: a randomized pilot trial. Complement. Ther. Clin. Pract. 20, 193-196. doi: 10.1016/j.ctcp.2014.07.001

Montgomery, G. H., Sucala, M., Dillon, M. J., and Schnur, J. B. (2018). Interest and attitudes about hypnosis in a large community sample. Psychol. Conscious. 5, 212-220. doi: 10.1037/cns0000141

Paoletti, G., Varanini, M., Balocchi, R., Morizzo, C., Palombo, C., and Santarcangelo, E. L. (2010). Cardiovascular and respiratory correlates of deep nociceptive stimulation, suggestions for analgesia, pain imagery and cognitive load as a function of hypnotizability. Brain Res. Bull. 82, 65-73. doi: 10.1016/j.brainresbull.2010.03.003

Pavlov, V. A., Chavan, S. S., and Tracey, K. J. (2018). Molecular and functional neuroscience in immunity. Ann. Rev. Immunol. 36, 783-812. doi: 10.1146/annurev-immunol-042617-053158

Perri, R. L., Facco, E., Quinzi, F., Bianco, V., Berchicci, M., Rossani, F., et al. (2020). Cerebral mechanisms of hypnotic hypoesthesia. An ERP investigation on the expectancy stage of perception. Psychophysiology 57:e13657. doi: 10.1111/psyp.13657

Piccione, C., Hilgard, E. R., and Zimbardo, P. G. (1989). On the degree of stability of measured hypnotizability over a 25-year period. J. Pers. Soc. Psychol. 56, 289-295. doi: 10.1037/0022-3514.56.2.289

Picerni, E., Santarcangelo, E. L., Laricchiuta, D., Cutuli, D., Petrosini, L., Spalletta, G., et al. (2019). Cerebellar structural variations in subjects with different hypnotizability. Cerebellum 18, 109-118. doi: 10.1007/s12311-018-0965-y

Poisbeau, P., Grinevich, V., and Charlet, A. (2018). Oxytocin signaling in pain: cellular, circuit, system, and behavioral levels. Curr. Top. Behav. Neurosci. 35, 193-211. doi: 10.1007/7854_2018_38

Presciuttini, S., Carli, G., and Santarcangelo, E. L. (2020). Hypnotizabilityrelated FAAH C385A polymorphism: possible endocannabinoid contribution to suggestion-induces analgesia. Int. J. Clin. Exp. Hypn. 68, 29-37. doi: 10.1080/00207144.2020.1682254

Rousseaux, F., Bicego, A., Ledoux, D., Massion, P., Nyssen, A. S., Faymonville, M. E., et al. (2020). Hypnosis associated with 3D immersive virtual reality technology in the management of pain: a review of the literature. J. Pain Res. 13, 1129-1138. doi: 10.2147/JPR.S231737
Russo, R., D’Agostino, G., Mattace Raso, G., Avagliano, C., Cristiano, C., Meli, R., et al. (2012). Central administration of oxytocin reduces hyperalgesia in mice: implication for cannabinoid and opioid systems. Peptides 38, 81-88. doi: 10.1016/j.peptides.2012.08.005

Sandvik, R. K., Olsen, B. F., Rygh, L. J., and Moi, A. L. (2020). Pain relief from nonpharmacological interventions in the intensive care unit: a scoping review. J. Clin. Nurs. 29, 1488-1498. doi: 10.1111/jocn.15194

Santarcangelo, E. L. (2014). New views of hypnotizability. Front. Behav. Neurosci. 8:224. doi: 10.3389/fnbeh.2014.00224

Santarcangelo, E. L., and Consoli, S. (2018). Complex role of hypnotizability in the cognitive control of pain. Front. Psychol. 9:2272. doi: 10.3389/fpsyg.2018. 02272

Santarcangelo, E. L., Paoletti, G., Balocchi, R., Carli, G., Morizzo, C., Palombo, C., et al. (2012). Hypnotizability modulates the cardiovascular correlates of subjective relaxation. Int. J. Clin. Exp. Hypn. 60, 383-396. doi: 10.1080/00207144.2012.700609

Santarcangelo, E. L., Paoletti, G., Chiavacci, I., Palombo, C., Carli, G., and Varanini, M. (2013). Cognitive modulation of psychophysical, respiratory and autonomic responses to cold pressor test. PLoS ONE 8:e75023. doi: 10.1371/journal.pone.0075023

Santarcangelo, E. L., and Scattina, E. (2019). Responding to sensorimotor suggestions: from endothelial nitric oxide to the functional equivalence between imagery and perception. Int. J. Clin. Exp. Hypn. 67, 394-407. doi: 10.1080/00207144.2019.1649539

Santarcangelo, E. L., Scattina, E., Carli, G., Ghelarducci, B., Orsini, P., and Manzoni, D. (2010). Can imagery become reality? Exp. Brain Res. 206, 329-335. doi: 10.1007/s00221-010-2412-2

Sari, N. K., Setiati, S., Taher, A., Wiwie, M., Djauzi, S., Pandelaki, J., et al. (2017). The role of autosuggestion in geriatric patients' quality of life: a study on psycho-neuro-endocrine- immunology pathway. Soc. Neurosci. 12, 551-559. doi: $10.1080 / 17470919.2016 .1196243$

Scavone, J. L., Sterling, R. C., and Van Bockstaele, E. J. (2013). Cannabinoid and opioid interactions: implications for opiate dependence and withdrawal. Neuroscience 248, 637-654. doi: 10.1016/j.neuroscience.2013. 04.034

Sebastiani, L., D’Alessandro, L., Menicucci, D., Ghelarducci, B., and Santarcangelo, E. L. (2007). Role of relaxation and specific suggestions in hypnotic emotional numbing. Int. J. Psychophysiol. 63, 125-132. doi: 10.1016/j.ijpsycho.2006 10.001

Spina, V., Chisari, C., and Santarcangelo, E. L. (2020). High motor cortex excitability in highly hypnotizable individuals: a favourable factor for neuroplasticity? Neuroscience 430, 125-130. doi: 10.1016/j.neuroscience.2020.01.042

Thompson, T., Steffert, T., Steed, A., and Gruzelier, J. (2011). A randomized controlled trial of the effects of hypnosis with 3-D virtual reality animation on tiredness, mood, and salivary cortisol. Int. J. Clin. Exp. Hypn. 59, 122-142. doi: 10.1080/00207144.2011.522917

Torem, M. S. (2007). Mind-body hypnotic imagery in the treatment of auto-immune disorders. Am. J. Clin. Hypn. 50, 157-170. doi: 10.1080/00029157.2007.10401612

Vanhaudenhuyse, A., Ledoux, D., Gosseries, O., Demertzi, A., Laureys, S., and Faymonville, M. E. (2019). Can subjective ratings of absorption, dissociation and time perception during "neutral hypnosis£ predict hypnotizability? An exploratory study. Int. J. Clin. Exp. Hypn. 67, 28-38. doi: 10.1080/00207144.2019.1553765

Walters, E. T. (2018). How is chronic pain related to sympathetic dysfunction and autonomic dysreflexia following spinal cord injury? Auton. Neurosci. 209, 79-89. doi: 10.1016/j.autneu.2017.01.006

Wortzel, J., and Spiegel, D. (2017). Hypnosis in cancer care. Am. J. Clin. Hypn. 60, 4-17. doi: 10.1080/00029157.2017.1290577

Xiong, W., Ping, X., Ripsch, M. S., Chavez, G. S. C., Hannon, H. E., Jiang, K., et al. (2017). Enhancing excitatory activity of somatosensory cortex alleviates neuropathic pain through regulating homeostatic plasticity. Sci Rep. 7:12743. doi: 10.1038/s41598-017-12972-6

Yin, Y., He, S., Xu, J., You, W., Li, Q., Long, J., et al. (2020). The neuropathophysiology of temporomandibular disorders-related pain: a systematic review of structural and functional MRI studies. J. Headache Pain 21:78. doi: 10.1186/s10194-020-01131-4 
Zhuo, M. (2020). Cortical plasticity as synaptic mechanism for chronic pain. J. Neural. Transm. (Vienna) 127, 567-573. doi: 10.1007/s00702-019-02071-3

Conflict of Interest: The authors declare that the research was conducted in the absence of any commercial or financial relationships that could be construed as a potential conflict of interest.
Copyright $\odot 2021$ Santarcangelo and Carli. This is an open-access article distributed under the terms of the Creative Commons Attribution License (CC BY). The use, distribution or reproduction in other forums is permitted, provided the original author(s) and the copyright owner(s) are credited and that the original publication in this journal is cited, in accordance with accepted academic practice. No use, distribution or reproduction is permitted which does not comply with these terms. 